\title{
Bernard Odendaal in gesprek met Charl-Pierre Naudé
}

Bernard Odendaal: Charl-Pierre, jy het in 1995 die Ingrid Jonker-prys vir jou debuutbundel Die nomadiese oomblik [Protea Boekhuis, 2004] gekry, en in 2005 sowel die Protea- as die MNet-prys vir Afrikaanse Poësie ingeoes met In die geheim van die dag (Geheim). Is literêre prystoekennings vir jou belangrik? Het dit volgens jou iets meer om die lyf as kommersiële waarde? Inspireer dit jou?

Charl-Pierre Naudé: Pryse dien beslis as inspirasie. En as die geld iets werd is, maak dit kuns moontlik wat dalk nie andersins sou gebeur het nie.

Maar prystoekennings is nie' $n$ foutlose proses nie. Van die beste werke kry nie pryse nie, of te laat. Omdat digkuns moeiliker by sy mark uitkom, is pryse vir die digkuns selfs belangriker!

Verder bevind ons ons in Suid-Afrika in ' $n$ tyd van manipulasie en verwardheid ten opsigte van kultuurwaardes. Daar is aan die een kant ou proteksionistiese houdings oor wat "ware kuns" is. Aan die ander kant bestaan'n situasie waar kultuurwaardes skaamteloos gemanipuleer word om nuwe (dikwels lofwaardige) politieke demografieë te bevorder.

Pryse het' $n$ besondere verantwoordelikheid, veral nou, om kultuurwaardes ongedienstig, dinamies en met intuïsie te bevorder.'n Tall order.

Odendaal: Tussen Die nomadiese oomblik en Geheim het tien jaar verloop. Skryf jy moeilik?

Naudé: Dit hang af van die soort werk. Die gedigte in Geheim en Against the light is'n moeilike soort. Ek het byvoorbeeld 'n Klipdrift-promosiegedig binne'n uur geskryf. Dis suiwer vrye vers en is meermale al gedoen. 'n Gedig soos "Die grond van die voorvaders" (in Geheim) en ander verse in die bundel het ek periodiek oor vier jaar aan geskaaf. Daar was nie in Afrikaans enige modelle vir hierdie soort poëtiese uiting nie, hoewel die aanvoorwerk daarvoor reeds bestaan het (Breytenbach, Van Wyk Louw, Petra Müller, Barend Toerien, selfs Louis Esterhuizen). 
Maar die laatste twee bundels het my nie tien jaar geneem om te skryf nie. Ek was besig met ander materiaal ook - 'n filmteks, 'n roman, en ek hou voortdurend notaboeke met idees, onder meer vir twee kortverhaalbundels, alles onvoorgelê.

Die eerste gedigte van die nuwe bundel is geskryf net voor 2000, 'n paar in 2000, en die res tussen Januarie 2001 en Desember 2004. Die hele bundel, is gelyktydig in Engels gekonsipieer. Dit was baie ambisieus, want die ritmiese en klankaspekte van die tale verskil. So, in genoemde vierjaartydperk het ek twee digbundels van nagenoeg 100 bladsye elk geskryf. Dis gemiddeld twee jaar - miskien twee en' $n$ half jaarper bundel. Miskien drie jaar vir die Engelse bundel. Die skawingsproses van Geheim, veral ten opsigte van die klankaspekte, was'n soort sublieme hel.

Odendaal: Van Against the light [Protea Boekhuis] gepraat: As jy dit gelyktydig met Geheim geskryf het, waarom het dit eers nou, in 2007, verskyn, twee en'n half jaar na Geheim? [Geheim het in Maart 2005 verskyn, hoewel die uitgewer die publikasiejaar as 2004 voor in die boek aangee.]

Naudé: Ek dink die "vertaling" was van meet af'n nuwe skeppingsdaad. Ek verkies die woord "oorsetting" of "nuutskepping". Die eerste fase was oor en weer: Ek sou die Afrikaanse weergawe skryf, en onmiddellik daarna die Engelse; of die Engelse, en dan die Afrikaanse. Heeltemal op gut feel. In hierdie fase het dit gegaan oor die inhoudelike: die idee, die emosie, die drama.

Tydens die tweede fase het die tale "geskei". Ek het eers volledig die Afrikaanse bundel tot stand gebring. Dis toe die metriese en klankaspekte voorop kom staan het, en dit kon beslis net in een taal op' $n$ slag gebeur.

Toe, daarna, het ek die Engelse weergawes by die Afrikaanses aangepas, en volledig net in Engels gewerk om die Engelse produk te kan "hoor", te kan "voel". By die verskyning van die Afrikaanse bundel was die Engelse een dus nog nie klaar nie.

Odendaal: Tydbelewing en werklikheidspersepsie, en die relatiwiteit daarvan, lyk vir my belangrik in beide Die nomadiese oomblik en Geheim/Against the light. Het daar ' $n$ tematiese fokusverskuiwing plaasgevind tussen die twee stelle bundels, en verklaar die verskillende bundeltitels iets hiervan?

Naudé: Ek dink daar is sekere temas wat deurlopend is. Geheim/Against the light is reeds "gebore" in die tweede helfte van Die nomadiese oomblik. Die tematiese fokuspunte is maar net verfyn. Die grootste verskuiwing is in die verhouding liries/verhalend. Ek het nog altyd twee inspirasies gehad: die liriese, en die verhalende. In Geheim en Against the light het die verhalende baie sterker na vore getree, en die liriese is meestal ondergeskik. (In slegs sowat'n derde van die bundel het dié twee aspekte'n 
gelyke profiel.) In Die nomadiese oomblik is dit andersom. Die hele tema van tydsbelewing word verder uitgewerk in Geheim en Against the light.

Odendaal: Die titels van beide Geheim en Against the light is geneem uit die slotgedigte van die bundels, onderskeidelik getiteld "'n Deur na binne" en "Against the light". Die slotgedigweergawes lyk dus na sleutelgedigte wat die tematiek in die bundels betref.

Naudé: Ja, slotte is sleutels. Die slotgedig in elkeen van die bundels gaan oor die persoonlike visie wat sal seëvier oor die kollektiewe. Oor die a-rasionele wat belangriker is as die rasionele. Oor die verhulde wat dalk veelseggender is as die sogenaamde liggewende.

Odendaal: Het ek reg dat nog so' $n$ tematiese sleutelteks in beide bundels die gedig "By die buitelandse persdinee" / "At the foreign correspondents' banquet" is?

Naudé: Dit is wel'n sleutelgedig, ja. Met hierdie gedig het die verhouding tussen die private en die politieke, wat die bundel(s) kenmerk, tot stand gekom. In'n sin wentel die tematiek van die bundel(s) rondom die volgende idee: "Hoe die politieke realiteite van die dag gedroom word in die lewe van die indiwidu." In Afrikaans én Engels in Suid-Afrika is gedigte meestal òf oor die private wêreld, òf oor die politieke wêreld -'n sintese tussen die twee is skaarser. Maar jy kry dit byvoorbeeld in Ingrid Jonker se kostelike trekarbeidergedigte [uit Rook en Oker] waar'n politieke dilemma uitsluitlik in private terme vergestalt word.

Ek wil meestal nie polities òf aktivisties skryf nie, maar bloot die noodlottige ineenskakeling van die politieke en private uitbeeld. Op'n wyse wat morele hoop skep. En spirituele ruimtes oopmaak.

Belangrik in genoemde gedig is die wisseling in die registers - van privaat na openbaar en weer terug; daar is ook'n vermenging van genre-elemente.

Odendaal: Dit is dus'n meerdimensionele kyk op die lewe en die wêreld waarin ons leef wat in hierdie bundel(s) gebied word. Lewe en dood, hede en verlede en toekoms, mitiese en historiese en eietydse gebeure, waarneming en herinnering en verbeelding, die ernstige en komiese, die politieke en private is almal dimensies wat in verskillende gedigte min of meer gelyktydig, en dikwels vervlegd, teenwoordig gestel word. Die gedig "Die brand" / "The brush" - in die Afrikaanse bundel vorm dit'n alleenstaande openingsgedig - is geskryf by die dood van die hond van ene " $\mathrm{C}$ ", en druk reeds iets hiervan uit. Of hoe? 
Naudé: Ja, die gedig handel oor die spreker wat sy meisie paai ná die dood van haar hond. Hy vertel haar: "Die hond is nie regtig dood nie, hy hardloop net agter'n duiker aan/op die boonste weiland." Dis maar "in sy aard". So, die lewe en die dood word as gelyke én gelyktydige leefmodusse voorgestel.

Die gedig wil hê die leser moet'n gedig van Catullus aan Lesbia oproep. Dis'n beroemde gedig in klassieke studies, waar Catullus'n bedroefde Lesbia beskryf nadat haar troetelvoëljie verkluim het. Die Catullus-gedig bevat' $n$ onbewuste komiese element, want die digter wil eintlik die aandag hê wat sy meisie aan die dooie voëltjie gee. My gedig eindig soortgelyk: "Kom nou, dit word laat."

Die gedig is'n mikrokosmos van die meeste van die aspekte wat jy noem en wat deurgaans voorkom.

Odendaal: Die meerdimensionele perspektief op werklikheid en tyd in Geheim/Against the light het my soms onwillekeurig herinner aan literêre strominge soos die surrealisme en die magiese realisme. Dit verras miskien daarom nie as name soos dié van Jan Blom [pseudoniem van Breyten Breytenbach], Charles Baudelaire, Salvador Dalí en César Vallejo opduik nie. Het skrywers en kunsstrominge soos die genoemdes jou inderdaad beïnvloed? Is daar nog inspirasiebronne wat jy sou wou noem?

Naudé: Ek kom agter dat ek in onderhoude verskillende digters as inspirasiebronne vermeld. Miskien verwar ek soms wie ek bewonder met wie my beïnvloed het?

Die surrealisme, meer as die magiese realisme, het my liriese sy sterk beïnvloed. Dit het begin by die invloed van Breytenbach, maar gou oorgegaan na invloede van buite. Die genoemde name is inderdaad belangrik. Maar ek sal graag wil dink dat die lewe - my eie en die lewe om my - my heersende invloed is.

Ek het alles gelees wat Uys Krige ooit geskryf en veral "vertaal" het. My poësie sou nooit eerste in Engels gebore kon gewees het nie. En Uys Krige is dalk die rede hiervoor!

Die Peruaanse digter Cesar Vallejo - van sy gedigte ook deur Krige vertaal - het my iets geleer van hoe "die verstand en die hart" kan saamdig. Dis die wesenskenmerk van wat ek sal noem die "post-surrealisme" - waarin die vryhede van die surrealisme weer aan die dwang van die intelligensie onderwerp word.

Maar laat ek maar iets sê oor enkele momente wat ek kan onthou wat miskien rigtinggewend was vir die narratiewe kant van my kreatiewe impuls. Ek beskou die gedig "Vlugtelinge" in Die nomadiese oomblik [ook in Groot Verseboek 2000 opgeneem] as die begin van Geheim en Against the light. Ek onthou nog die gedig wat in my agterkop gespook het terwyl ek dit geskryf het: "Arlésiennes" van Van Wyk Louw, uit sy Nuwe Verse. Het Harold Bloom nie geskryf oor die voorbeeld/model uit die werk van'n voorganger wat in die digter se kop spook wanneer hy iets nuuts probeer doen nie? Ek wou iets doen wat Louw daar doen, maar ook iets heel anders. 
'n Ander stem het ook by my gespook: Raymond Carver, die Noord-Amerikaanse digter en kortverhaalskrywer s'n. Ook dié van die Poolse digter Ceszlaw Milosz. Albei laasgenoemdes werk met'n spreektaal-inslag. (Carver werk amper uitsluitlik met die colloqual voice, waar myne sowel as Milosz s'n - én Louw se klassieke prosodie - meestal'n innerlike, nadenkende stem is.)

Ek dink vandag "Vlugtelinge" is baie prosa-agtig vergeleke met wat ek doen in Geheim en Against the light. En juis dít was die moeilikste aspek in die skryf van beide Against the light en sy Afrikaanse eweknie: om die reëls uit te trek na soms 22 lettergrepe, sonder dat die metrum kantel. Ek het dit gedoen om 'n elegiese, hipnotiese ritme te kry, wat nie te vroeg deur enjambement onderbreek word nie.

Nog'n keermoment vir my, uit my prille jeug, het my'n paar dae gelede bygeval. Dit was toe ek vir die eerste keer Ezra Pound se Selected Poems, met die voorwoord deur T. S. Eliot, onder oë neem. Daar is ' $n$ afdeling daarin, "Cathay", van Chinese gedigte wat deur Pound omgedig is.

Ek onthou dat ek'n Afrikaanse vertaling of twee, onder meer van die gedig "The river-merchant's wife: a letter" in 'n Afrikaanse little magazine gelees het in 1982 - en die skok van herkenning! Die narratiewe been van my inspirasie was dalk op daardie moment gebore. Hier was'n storiegedig, vol allusie. En dit in "gewone taal".

By die lees van die ander "Chinese gedigte" van Pound het ek veel van my eie muse gesien in hierdie aspek van "allusie". Carver het dié proses so beskryf: "To imbue the most everyday object or experience with symbolic value."

Overgesetsynde: die narratief bevát nie soseer beelde nie, dit ís die beelding, Dit bevat "'n storie agter die storie", in simboliese taal. Die gedig self, in sy geheel, word 'n simbool.

'n Opvallende aspek van vele gedigte in Geheim en Against the light, by terugskoue, is wat Gus Ferguson in'n resensie conceits noem. Ek beskou dit as dalk die belangrikste aspek van my digkuns. Minstens tien gedigte, en dalk meer, wentel om 'n conceit 'n skuif wat werk soos oëverblindery, en daardeur die voorafgaande heeltemal op sy kop draai. Dit kom gewoonlik teen die einde van'n gedig aan die bod.

Daniel Hugo het verwys na my eerste bundel as gekenmerk deur "hiperrealisme". Ek dink dis steeds van toepassing. "Hiperrealisme" veronderstel'n meer soomlose oor-en-weer-verskuiwing tussen die reële en die irreële. Die persepsie kantel net so'n klein bietjie; nie te veel nie ...' $n$ vorm van histerie - en 'n onverwagse kier ontstaan. 'n Pandoraboks van die versweë gaan hopelik so oop.

Odendaal: Elke afdelingstitel in die bundel, asook heelparty gedigtitels, is verdere opvallende sinjale van so'n deureenspeling van belewingsmodusse en eras. Vergelyk maar net uit Geheim: "Paddas reën", "Die towertyd", "Tasbaar en ontasbaar", "Voorvadergrond", "Kruispaaie", "Tweerigtingspieël”, "Tweespraak" en "Tydvakke". Die titel van die sesde afdeling in Geheim is "Semafore". Wat is semafore, en hoe pas dié titel binne die konteks van die res van die bundel? 
Naudé: In die dae voor die verfyning van radar het daar'n semafoor op die aanloopbaan gestaan en die vliegtuie na hul staanplekke ingewuif. Hy sou so ' $n$ "bord" in sy hande hou en afhangende van hoe hy dit draai, kry jy'n kommunikasie met die loods in die vliegtuig. Ek dink jy het hulle ook in hawens gekry.

Die woord verwys volgens my na die volgende stylaspek van my bundel: Betekenisse is nie in die woorde self teenwoordig nie, daar word slegs daarna geskimp; die betekenisse lêagter die woorde. Tradisioneel in die Suid-Afrikaanse poësie, in Afrikaans én Engels, kom betekenisse tot stand deur middel van die tekstuur van die woord. Die betekenis is meer immanent aanwesig, selfs by Breytenbach, en dis ook die vernaamste verskil tussen sy "surrealisme" en myne.

Hierdie aspek van "geskimpte betekenis" is ook'n sentrale aspek van die simbolisme, en die post-surrealisme.

Ek kan hierdie verskil - tussen "tekstuurgedigte" en "verbeeldingsgedigte" - belig deur te verwys na die voorwoord deur die Amerikaanse kritikus J. D. McClatchy in sy bloemlesing van 'n paar jaar gelede, The Vintage Book of Contemporary World Poetry [ISBN: 0-679-74115-1]. Daarin sê hy jy kry twee soorte inspirasies in die digkuns: die invented en die received. Eersgenoemde werk met die "technical apparatus and rhythmical instincts [of a language] [...] the whole echo chamber of a [particular] tradition. These are the hardest [poems] for a translation to catch." En só praat hy oor die tweede inspirasie: "The second inspiration is the 'received'. Hegel thought that the true medium of poetry is not words but 'poetic ideas'. [...] [The poem] as a manifestation of an invisible poem, written in a language beyond languages. Such invisible poems reveal themselves less in the actual lines of a poem than in the figures those lines conjure up."

Die Afrikaanse tradisie, sowel as die Britse en die grootste deel van die Nederlandse, het histories meer gewerk met die eerste soort inspirasie. My gedigte werk weer meer met die tweede inspirasie, the received. McClatchy gaan dan aan om te sê dat sulke gedigte makliker vertaal as die eerste soort omdat die gedig self "soos' $n$ vertaling is" - van die "onsigbare oorspronklike".

Die een inspirasie is egter nie meer belangrik as die ander een nie. Maar as ek egter lees wat P. G. du Plessis onlangs in Beeld sê: "Die javels wat deesdae gedigte skryf. Waar is die musiek?" - dan wonder ek: het hierdie tweede inspirasie, wat al so lank deel is van die Europese gedagtewêreld, al na behore deel geword van die Afrikaanse verwagtingshorison?

Odendaal: Het laasgenoemde inspirasiebasis dit na jou mening makliker gemaak om Geheim in die Engelstalige Against the light om te sit?

Naudé: Ek dink beslis so, Bernard. Dit sal interessant wees om Breyten se nuutverskene Windcatcher (uitgegee deur Harcourt) te vergelyk met sy Afrikaanse bundel 
van vroeër vanjaar. Die betekenis-eggo's by hom gaan meestal uit van die klankfluisteringe. 'n Onbegonne taak vir'n vertaler - so voel dit vir my!

Odendaal: Die slotgedig van Against the light eindig, soos ongeveer die slotgedig van die Afrikaanse bundel, met die woorde "the secrets / of daylight" (in Afrikaans "in die geheim van die dag", wat toe ook die bundeltitel geword het). Waarom het jy vir die Engelse bundel die titel Against the light gekies?

Naudé: Dis maar net' $n$ radikale omdigting van dieselfde idee as "In die geheim van die dag": iets is verhul, of iets wat verhul was, word bekend.

As mens na iets teen die lig kyk, kan jy verblind word, en so die voorwerp glad nie sien nie. Alternatiewelik, as mens iets teen die lig hou (soos' $n$ negatief van' $n$ foto), kan jy dalk die eeerste keer die ware aard daarvan sien. Daar is dus' $n$ tweerigtingbetekenis.

Maar meer belangrik: om die arrogansie van dit wat reeds geopenbaar is, te wantrou.

Verder: die titel In die geheim van die dag bevat nog iets van die hoop in die dekade ná apartheid. Against the light reflekteer'n pessimisme, wat sê: Moenie laat' $n$ ander sy/haar Damaskuservaring as die enigste op jou afdwing nie!

Odendaal: Nog iets oor die verskille tussen Geheim en Against the light: Gedigte van die Afrikaanse uitgawe staan ingrypend geskommel in die Engelse. Nie slegs is die volgorde van die gedigte in sommige afdelings verander nie; op groot skaal is verse oor afdelinggrense heen-en-weer geskuif, sodat soms nuwe afdelings of nuwe afdelingstitels ontstaan het. Selfs die volgorde van die afdelings is geskommel. Twee van die gedigte uit die Afrikaanse bundel ("'n Antieke literêre fragment" en "Die rose") is weggelaat. En steeds het ek nie al die aanpassings genoem nie ... Hoekom al die verskille? Is die Engelse weergawe dan eintlik' $n$ "selfstandige" bundel?

Naudé: Beslis is dit' $n$ selfstandige bundel, Bernard. Ek het ander indelings gekies, want om bepaalde redes wou ek ander klemtone plaas. Ek weet steeds nie waarom nie; dit was intuïtief. Ek kan sien dat die langer gedigte nou meer na agter verskyn. Dis vir my'n verbetering: trek eers die leser in, en kom dan met die langer verse. Die vaart van voor na agter stuit dus nou teen minder hindernisse.

Oor die twee gedigte wat ek weggelaat het: "Fragment" is te gedronge en sinteties om die nugter aard van die bundel gestand te doen. En in die geval van "Rose" ... wel, ek hou nie meer van die gedig nie.

As jy die voorblad van Geheim en Against the light met mekaar vergelyk, kan jy sien hoe die "vertaalproses" reeds daar begin. Die struktuur en die ritme van die twee voorstellings eggo mekaar:'n figuur wat wegkyk op die voorgrond, wat iets geheim- 
sinnigs uitstraal, teen' $n$ agtergrond wat'n paradoks aktiveer. Die "metafoor" is iets soortgelyks, maar die inhoudelike verskil. Hieraan kan jy sien hoe radikaal die "omdigtingsproses" soms kan wees.

Odendaal: Een van die boeiendste aspekte van die bundel is dat elke gedig iets verrassends of raaiselagtigs bevat, en dikwels met humor aangebied.

Naudé: Die humoraspek is belangrik. Dit maak dat die gedigte hulself nie te ernstig opneem nie. Daar is 'n teatrale, hiperboliese dimensie. Dis seker deel van die "histerie"-element waarna ek verwys.

En die verteller in die gedigte is ' $n$ bra onaf persoon, Bernard. Dié dat hy so knaend verras word. Sal jammer wees as hy nie ook kan lag nie.

Odendaal: 'n Ander bewonderenswaardige kenmerk van jou bundel(s) is dat die gedigte geheimsinnighede bevat, maar tegelykertyd glashelder is. Die gedigte, ek weet eintlik nie hoe om dit te benoem nie, lyk of dit êrens tussen prosa en liriese poësie te staan kom - of moet ek liewer sê: bevat elemente van albei genres. Sommige is selfs kortverhaalagtig. Waarom het jy op dié styl en vormgewing besluit?

Naudé: Ek praat hierbo van die verskil tussen "verbeeldingsgedigte" en "tekstuurgedigte". Eersgenoemde het baie meer speling nodig. Ek sou nooit die geheimsinnighede, soos jy dit so mooi noem, kon ontgin as ek meer konvensionele poëtiese vorme gebruik het nie.

Ek het ook baie sterker aandag in die nuutste twee bundels gegee daaraan om die emosionele, die menslike ervaring, die drama, immanent teenwoordig te kry. Met ander woorde, die taal - wat die medium is - moet op die agtergrond geskuif word. Soos met 'n rolprent, wil ek die illusie skep dat die medium - die taal, hier - nie tussenbeide kom nie, dis net "'n getjir in die agtergrond". Om taalstruktuur "onsigbaar" teenwoordig te kry, is egter nie so maklik nie. Die metrum moet reg geryg wees. En'n klankie op die verkeerde plek maak dit juis sigbaar.

Ek werk met die meer onooglopende klankbindingsmiddele: halfrym pleks van volrym, assonansie pleks van binnerym, ensovoorts - en as daar volrym is, plaas ek die woorde opsetlik ver van mekaar sodat dit slegs'n eggo bly.

(Ek dink só aan die verskil tussen die meer konvensionele vers en hierdie: jy kry styfgeweefde kouse, met klein gaatjies. En jy kry los geweefde kouse, met groot gaatjies. 'n Visnet-kous is nie makliker om te weef as'n paar "tights" nie. Trouens, dit kan veel makliker skeeftrek!)

Die kombinering van helderheid en geheimsinnigheid is belangrik. Geheimsinnigheid moet nugter aangebied word, anders is dit mistifikasie. 
Ek sou nie die gedigte as prosagedigte tipeer nie. Daar is wel een prosagedig in die bundels, naamlik "Tweespraak" / "Classical dialogue". Een van die moeilikste aspekte in albei bundels was juis die reëlbreuke. Maar, ja, dis'n soort poësie met die voorkoms van prosa, selfs die kortverhaal ... maar dit is nie dit nie.

Ek dink nie aan die verhalende gedigte in die bundel eers as vrye vers nie! Die skryf daarvan het my meermale laat dink aan die skryf van sonnette - net veel moeiliker.

Odendaal: Het ek reg dat die Engelse vertalings in Against the light soms korter versreëls het as die Afrikaanse ekwivalente? Het jy dit doelbewus gedoen, en met watter effek in gedagte?

Naudé: Nee, dis per ongeluk. Die Engelse reëls en die Afrikaanses breek op verskillende plekke weens die verskille in ritmiese voorskrifte in die twee tale. Maar die idee-inhoud word ook beïnvloed deur reëlbreuke: Ek het soms dae lank oor een enkele enjambement getob, veral by die Engels.

Odendaal: Die langste gedig in die bundel(s) is die versinde dramatiese tweespraak (mét toneelaanwysings) tussen die Latynse digters Catullus en Horatius wat jy genoem het as moontlike voorbeeld van' $n$ prosagedig. In die Afrikaanse bundel bring die gedig "'n Antieke literêre fragment, ontdek in 'n kelderverdieping" weer vir Catallus onder die leser se aandag. Wat, by wyse van spreke, maak hierdie antieke Romeinse digters in jou bundel? Catullus word redelik algemeen beskou as die grootste hartstogtelik-liriese digter van antieke Rome, veral bekend vir sy liefdespoësie en selfopenbaring. Daarenteen verteenwoordig Horatius veral die poëtika van gematigdheid, van serene, lig-ironiese besinning. Is elemente van beide poëtikale houdings in die bundel terug te vind.

Naudé: Ek het hierdie twee digters die eerste maal op skool in die Latynklas teëgekom. Hulle is vir my prototipes van twee poëtiese ingesteldhede - soos jy so akkuraat hierbo beskryf - wat die voorkoms van die latere Westerse digkuns bepaal het.

Maar meer belangrik: Horatius was pro-staat en pro-orde; Catullus was by implikasie anti-staat en anti die orde. Dis waarvoor'n Suid-Afrikaanse skrywer ook vandag te staan kom - in'n konteks waar die keuse nie so voor-die-handliggend is as tydens die vorige bedeling nie. Ek kies uiteindelik vir die voorbeeld van Catullus.

Odendaal: Die prosodie in jou bundel is miskien nie sangerig-liries nie. Maar dit maak dié eiesoortige verskuns nie minder beheersd of gestileerd nie. Ek wil net' $n$ paar uitstaande indrukke noem wat ek betreffende die digstyl het in Geheim/Against the light: noukeurigheid van woordkeuse; vindingryke, meermaals pragtige beeld- 
spraak en treffende woordspel; milde ironie en humor; klanksensitiwiteit; verlewendiging van idiomatiese en geykte uitdrukkings. Op innemende wyse word sulke elemente, tesame met' $n$ ryke verwysingsveld, vermeng met gemeensame gesprekstaal. Laasgenoemde word benadruk deur die talle aanwysende vorme, uitroepe, verkleiningsvorme en vraagstellings wat die bundel deurspek. Dit alles sorg vir een van die boeiendste leeservarings wat ek in'n lang tyd gehad het.

Naudé: Dankie, Bernard. 